\title{
Expert System of a Sewage Treatment Plant for Wood Industry
}

\author{
J. Bouza-Fernandez ${ }^{1}$, G. Gonzalez-Filgueira ${ }^{1}$, S. de las Heras Jimenez ${ }^{2}$, D.Vazquez-Gonzalez ${ }^{1}$ \\ ${ }^{1}$ University of A Coruña. Avda. 19 de Febrero s/n, 15405. Ferrol, Spain, \\ e-mail: jbf@udc.es, gerardog@udc.es,dvg103@hotmail.com \\ ${ }^{2}$ Politechnical University of Catalunya, 08222 Terrassa, Spain, e-mail: delasheras@mf.upc.edu
}

\begin{abstract}
This paper describes the methodology and solution to automate and monitor a sewage treatment plant from an industry dedicated to the manufacture of wood panels. The control system designed, not only governs all elements of performance of the plant, but also oversees its proper functioning. It also has a human-machine interface with a daily working and emergency program, accompanied by an information system supported by records and alarms to facilitate human decisions making if were necessary. The proposed solution, not only increases the reliability and safety of the process with respect to plants or other type semi-automatic operation, but also reduces costs by improving process efficiency and minimizes costs in maintenance and monitoring.
\end{abstract}

\section{Introduction}

Nowadays the field of centralized control is linked to major production processes or industrial applications, where the flow of information allows optimizing the total production process. In the area of small to medium enterprises (SMEs) [1], however it is still underdeveloped [2]. Perhaps the reason is not the lack of capacity for the design or the cost of the technology, but the lack of vision and lack of skills, in addition to the benefits obtained with this type of automation. Added to this that the current diversity and technological capability allows to choose a wide range of both technical and economic possibilities. As a result, it is possible to select the technology in order to balance the binomial needs-costs.

In this line shows an application of centralized control, that is linked to a sewage treatment plant [3][4] for the timber industry, as a solution that not only reduces costs in human resources, but also increases the reliability and safety of the process compared to plants that operate semi-automatically and even, with respect to distributed control systems. Thus, from a single control element you can manage, monitor and supervise, in real time, the whole system.
As a starting point for this project, a sewage plant (Fig. 1) which operates semiautomatic and with permanent presence of several operators to carry out the monitoring and supervision of the installation has been chosen. The system proposes that it should be possible to reduce the human presence to a single operator from a single point of control and that may be simultaneous with other plant processes. In addition to synchronize the various processes of the plant in order to improve the efficiency of the system, which affect the costs of production and levels of quality obtained in the purification process. Finally it is vital to minimize "human error" providing the operator with accurate and timely information accompanied by a set of records and alarms. This will increase the security of the system, and therefore, also, it will avoid any possible risk of environmental contamination.

\section{Used Method}

From a technological perspective, the following requirements for the development of the system control have been established:

a) Take advantage of, where possible, equipment and processes of the plant that is the object of this study.

b) The control system must govern all elements of the wastewater treatment plant performance, and monitor its

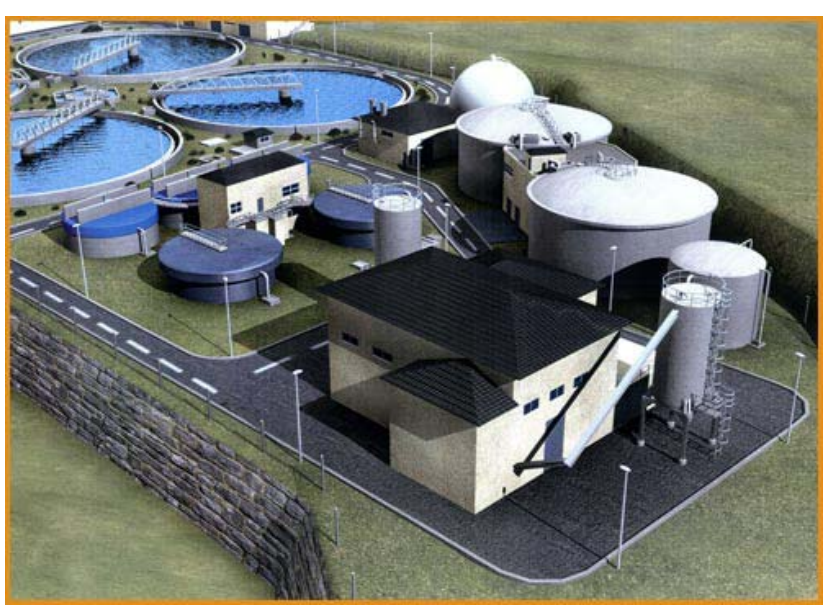

Figure 1. Sewage Treatment Plant. 
proper functioning.

c) A program must be available for their daily operations and for emergencies and maintenance.

d) Provide clear and detailed system status, based on records and alarms, to facilitate human decisions making, if were necessary.

On the basis of these requirements, and prioritizing the relation cost-versatility, for the implementation of the system the following were chosen:

a) A series PLC Siemens S7-200 control system [5][6][7].

b) "WinCC Flexible SCADA" Siemens Software to design and monitor the Human-machine interface [8][9] (Fig. 2).

c) Re-using of existing equipment when it not minimizes the requirements for the control system. Elements strictly necessary are added for increasing the efficiency of the system.

The objective of the control system is to improve efficiency and quality of the whole process of purification in two aspects:

a) On the one hand it involves a study of the process restructuring it or modifying those steps or elements deemed inefficient.

b) In the other hand it provides continuous monitoring of sewage treatment. Also displays historical process data and manage the process notices provided by the system.

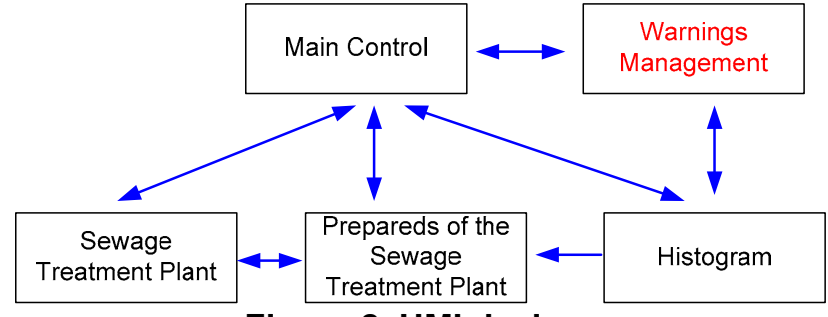

Figure 2. HMI design.

This not only allows real time monitoring of the plant but also to make predictions or future prospects.

There is a relationship between the different elements of the control system SCADA and the work they do within the system. With these automated systems achieve optimize sewage treatment with comparison of actual and theoretical graphics. Modification of the existing situation assumptions are made and are valued, quantifying their effects to the objectives set. Therefore, the objective of operation of the plant is granted.

\section{Description Plants Process Control}

The process of purification consists of the following processes (Fig. 3): Filtering, elimination of the colloids through the process physical-chemical clotting and flocculation, treatment to regulate the $\mathrm{Ph}$ of the water,

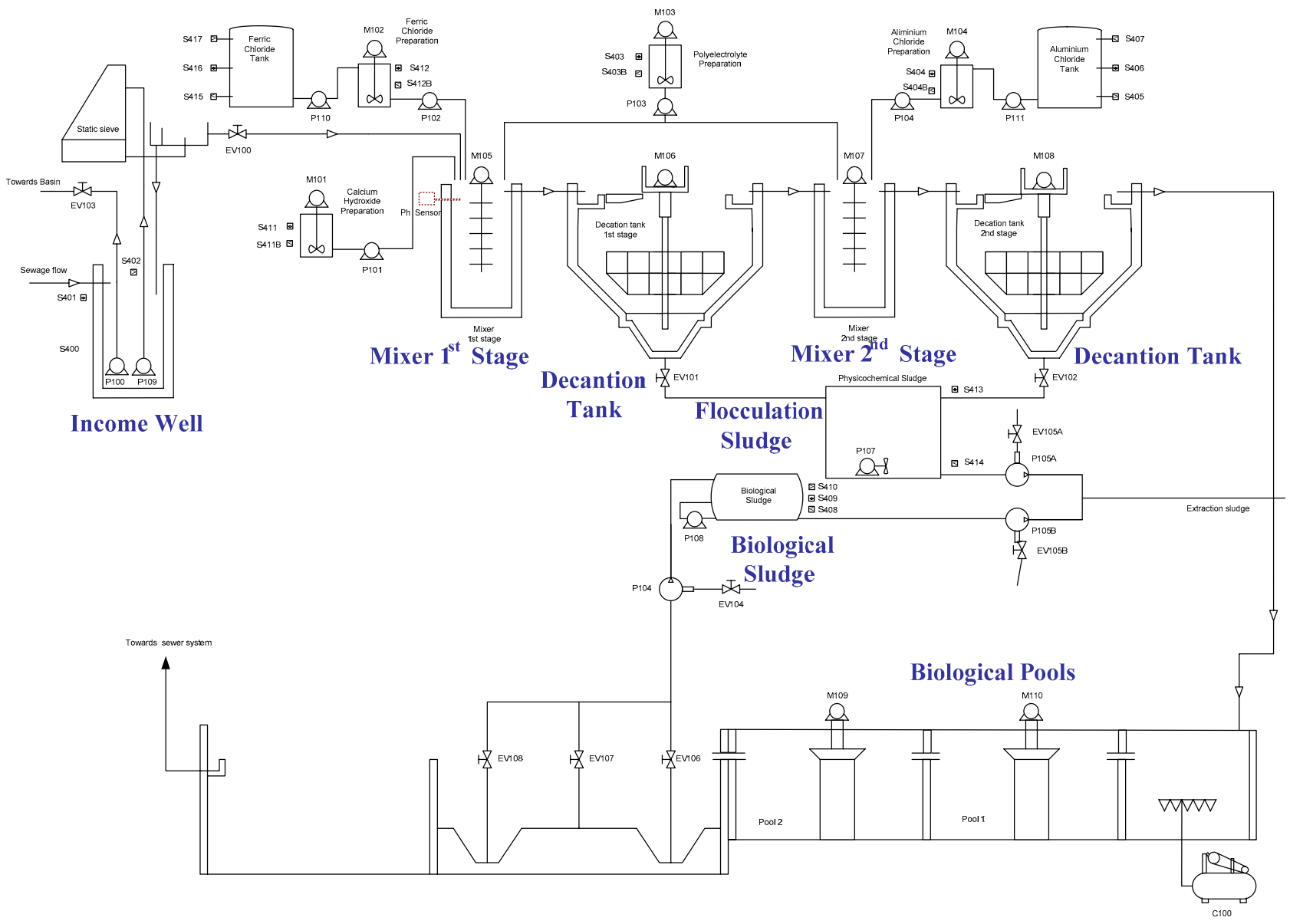

Figure 3. Sewage Treatment Plant Scheme. 
biological treatment and finally, decanting and sludge extraction.

The water to be treated is stored in a basin, the purification process starts when the water enters the storage basin at the entrance well, in the well there is a pump that constantly circulates the water towards a static sieve which takes care of the solid waste. Once the water from the entrance well reaches the work level, it is directed to the mixer of the first stage.

In the mixers of the $1^{\text {st }}$ and $2^{\text {nd }}$ stage a variety of preparations will be added to water: ferric chloride, polyelectrolyte and aluminium chloride, to decant the water pollutants by coagulation and flocculation (process where colloids come out of suspension in the form of floc or flakes), in a solid waste called flocs. In order that this process takes place under optimum conditions of $\mathrm{pH}$, calcium hydroxide will be added at the $1^{\text {st }}$ stage. A motor will be continuously working throughout the process for mixing the different chemicals preparations to water. The waste water treated with these agents will be moved to some decanters in where the solid remains of the process, or flocs, will collect and will be stored in a deposit for that purpose. And the cycle of waste water treatment by biological treatment in pools will continue.

In the pools, the "biological treatment", it is made by the growth of a bacterial flora that eats dirt. The $\mathrm{Ph}$ level in the pools should not be very high because but bacteria responsible for the purification will not carry out its work correctly as it will protect itself due to the high $\mathrm{Ph}$ level. There is also in these pools a flow of sludge, which is removed in proportion to the water flow in it. In this way the excess of bacterial population is removed and recycled at the same time, which in turn maintains its capacity for purification. To maintain a level of oxygenation appropriate in the pools, air is injected, producing a bubbling of air from the bottom together with the action of some ventilators.

Both the sludge from the decanters and sludge extracted [10] from the pools of biological treatment will be removed to some tanks. In these tanks will be working some motors to prevent it from solidifying. To remove the sludge from the tanks will be used some pumps operated by some air motors, taking advantage of the air installation that exists to inject air into the pools.

\section{Algorithm for Process Control}

The control system must govern all elements of performance of the sewage treatment Plant, and monitor its proper functioning. Moreover, it has to have a program for its daily operations and emergencies. All this accompanied by an information system supported by records and alarms to facilitate human decisions making, if were necessary. The control system may operate automatically according to operating programs daily and/or manually in case of emergency or tuning on.

The expert system specifications for this process are: a) SCADA System:

- Display and management of real time processing.

- Displays alarms and warnings.

- Display alarm history, and notices.

- Information about the protocol for each alarm or warning activated.

- Two way communication with S7 PLC.

b) The PLC Program:

- Include functions and sequences of the plant standards.

- Must establish procedures for cases of failure or emergency. With warning signs and alarms well marked.

- Structured programming to facilitate any changes or upgrades.

- Allow two-way communication with the SCADA system [11][12].

- Reading and interpreting all types of signals: analogue or digital

- Control and supervision of the actuators and field elements.

Normally, in each of the control processes in a plant we choose a programmable automation model. The process used here is continuous. The process involved in water waste removal can be separated into in different stages that must happen sequentially and correctly. Once the plant specifications have been laid down we continue to programme the plant design, a descending design "top-down" is used. Due to need for an algorithm as open as possible, in order to be able to work in different PLC's, depending on the needs of clients, and the capacities of the system, the GRAFCET of the second level represents the flow diagram of the states of the process (Fig. 4). The algorithm is implemented following the structure of the program. Following the requirements of the system indicated previously, a language program of contacts that satisfies the specifications has been implemented.

The Table I and the Table II contain the description of input and output variables respectively used in the program. The analysis of GRAFCET concluded that there is a cycle of working with seven processes that operate simultaneously or selectively. The activation of each of the processes will depend on the necessity to activate the process in question [13]. The processes of the system are following:

(a) Branch 1: "Water filling process". It starts with the "starting up" of the system and when the sensor S400, minimum level of water in the entrance well, is activated. Under these circumstances the pump P109 will start which will circulate water from entrance well through the static sieve. Then it will open the valve EV100 that will allow the passage of water to $1^{\text {st }}$ stage mixer. When sensors S401, due to work level, and S402, due to maximum level of water, are activated in the well, it will launch the P100 pump and will open the EV103 valve to discharge excess water from the entrance well 


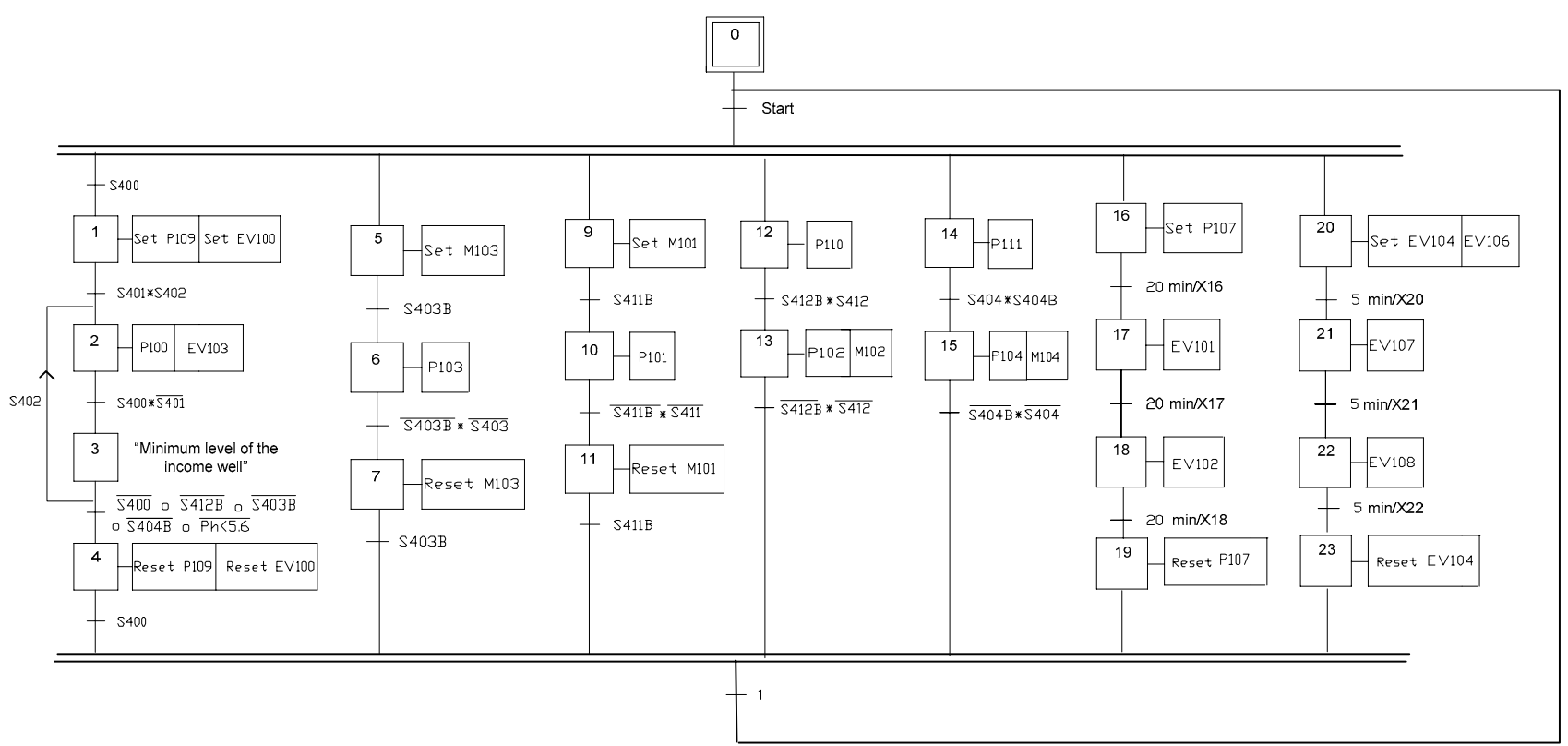

Figure 4. Level 2 GRAFCET.

towards the pool. This latter process will stop when the water in the well reaches the minimum level. The activation of the P109 pump and of the EV100 valve that cause water to flow into the other stages, will be cancelled if any of the sensors of minimum level of the tanks of preparation are activated (ferric chloride or polyelectrolyte or aluminium chloride) or if the $\mathrm{Ph}$ level in the "Mixer for $1^{\text {st }}$ stage" is less than 5.6.

b) Branch 2: "Process of polyelectrolyte preparation": When activating the "Start-up", this starts the M103 motor that turns the contents of the tank that contains the polyelectrolyte preparation and the water to mix. If the S403B sensor is activated, which is the minimum level of the deposit, the P103 pump, will be activated and this is responsible for providing the preparation to the mixer $1 \mathrm{st}$ and 2 nd stage. If minimum level sensor is disabled or the emergency stop is activated, the motor of remover in the tank of prepared of polyelectrolyte will stop.

c) Branch 3 "Process of calcium hydroxide preparation". When activating the "Startup", it starts the motor M101 responsible for mixing the calcium hydroxide prepared solution in the preparation tank. If the S411B sensor minimum level of preparation is activated, the P101 pump which provides the mixture of the $1^{\text {st }}$ stage will be activated. Disabling the minimum level sensor of preparation (S411B) or activating the emergency stop will stop the M101 motor.

d) Branch 4: "Process of Ferric Chloride Preparation". With the system in motion the P110 pump that supplies ferric chloride to preparation tank to reach the maximum level detected by S412 sensor. Then in turns starts the M102 motor, responsible for removing the preparation, and the P102 pump that supplies the preparation in $1^{\text {st }}$ stage mixer. Disabling the prepared minimum level S412B sensor or activating emergency stop, the M102 motor and P102 pump will stop.

e) Branch 5: "Process of Aluminium chloride preparation". It is similar to the branch 4 , by changing the designation of sensors and actuators. Its output is the mixer stage 2 , instead of stage 1 . With the system in motion, the P111 pump starts which supplies aluminium chloride preparation in the deposit up to the maximum level detected by S404. Then it will launch the M104 engine, responsible for mixing the preparation, and the P104 pump that supplies the preparation in 2nd stage mixer. Disabling the prepararation minimum level S404B sensor or activating emergency stop, will stop the M104 motor and P104 pump.

f) Branch 6. "Process of physical-chemical sludge removal": When activated the "Startup" in the SCADA panel, the submersible P107 mixer is put into operation that ensures the physical-chemical sludge does not solidify. Twenty minutes after the process starts, the EV101 opens to extract the sludge from decanter of $1^{\text {st }}$ stage for another 20 minutes. Immediately the EV101 closes and the EV102 opens to remove, in this case, the sludge from the decanter of $2^{\text {nd }}$ stage for another 20 minutes. This cycle is repeated continuously unless the process is stopped.

g) Branch 7: "Biological sludge Extraction Process". When "Startup" on SCADA panel is activated, it starts the EV104 valve that operates the P104 pump, responsible for the extraction of biological sludge, and opens EV106 valve that connects the aspiration of the pump. After 5 minutes, the EV106 closes and the EV107 and EV108 valves opens for another 5 minutes each alternately connecting to the pump suction.

Finally, "the emergency stop". If emergency stop in the SCADA is activated the entire installation will stop and remain locked until reset is activated. The activating 
TABLE I

PROGRAM INPUTS

\begin{tabular}{|c|c|}
\hline Inputs & Function: Level Sensors \\
\hline $\mathrm{I} 0.0$ & Minimum level. Income Well (S400) \\
\hline I0.1 & Reference level. Income Well (S401) \\
\hline $\mathrm{I} 0.2$ & Maximum level. Income Well (S402) \\
\hline $\mathrm{I} 0.3$ & Maximum level. Ferric Chloride Preparation (S412) \\
\hline $\mathrm{I} 0.4$ & Minimum level. Ferric Chloride Tank ( S415) \\
\hline $\mathrm{I} 0.5$ & Reference level. Ferric Chloride Tank (S416) \\
\hline I0.6 & Maximum level. Ferric Chloride Tank (S417). \\
\hline I0.7 & $\begin{array}{l}\text { Maximum level. Calcium Hydroxide Preparation } \\
\text { (S411). }\end{array}$ \\
\hline $\mathrm{I} 1.0$ & Maximum level. Polyelectrolyte Preparation (S403). \\
\hline I1.1 & $\begin{array}{l}\text { Maximum level. Aluminium Chloride Preparation } \\
\text { (S404) }\end{array}$ \\
\hline $\mathrm{I} 1.2$ & Minimum level. Aluminium Chloride Tank (S405). \\
\hline $\mathrm{I} 1.3$ & Reference level. Aluminium Chloride Tank (S406). \\
\hline I1.4 & Maximum level. Aluminium Chloride Tank (S407). \\
\hline $\mathrm{I} 1.5$ & Minimum level. Biological Sludge Tank (S408) \\
\hline I1.6 & Reference level. Biological Sludge Tank (S409). \\
\hline $\mathrm{I} 1.7$ & Maximum level. Biological Sludge Tank (S410). \\
\hline $\mathrm{I} 2.0$ & $\begin{array}{lll}\text { Maximum level. Physicochemical } & \text { Sludge } \\
\text { Tank(S413). } & & \\
\end{array}$ \\
\hline $\mathrm{I} 2.1$ & $\begin{array}{l}\text { Minimum level. Physicochemical Sludge Tank } \\
\text { (S414). }\end{array}$ \\
\hline $\mathrm{I} 2.2$ & $\begin{array}{l}\text { Minimum level. Ferric Chloride Preparation } \\
\text { (S412B). }\end{array}$ \\
\hline $\mathrm{I} 2.3$ & $\begin{array}{l}\text { Minimum level. Aluminium Chloride Preparation } \\
\text { (S404B) }\end{array}$ \\
\hline $\mathrm{I} 2.4$ & $\begin{array}{l}\text { Minimum level. Calcium Hydroxide Preparation } \\
\text { (S411B). }\end{array}$ \\
\hline $\mathrm{I} 2.5$ & $\begin{array}{l}\text { Minimum level. Polyelectrolyte Preparation } \\
\text { (S403B). }\end{array}$ \\
\hline Inputs & Function: Analog Sensors \\
\hline AIW0 & $\mathrm{Ph}$ value. Mixer $1^{\text {st }}$ Stage \\
\hline AIW2 & Temperature. Mixer $1^{\text {st }}$ Stage \\
\hline Inputs & Function: Memory \\
\hline M0.0 & Start \\
\hline M0.1 & Emergency Shutdown \\
\hline M0.2 & Reset of the System \\
\hline M0.3 & Empty income Well \\
\hline M1.0 & Emergency Shutdown Light \\
\hline M1.1 & $\begin{array}{l}\text { Set/Reset of EV101 \&EV102. Drain valves of } \\
\text { Decantion Tanks }\left(1^{\text {st }} \& 2^{\text {st }} \text { stage }\right)\end{array}$ \\
\hline M1.2 & Set/Reset EV105A. \\
\hline M1.3 & Set/Reset EV105B. \\
\hline
\end{tabular}

the emergency stop paralyzes all motors and pumps and puts the valves in a stand by position, leaving different system processes to be automatically locked until the system is rearmed.

\section{Theoretical Analysis}

One of the important aspects of the process is the need to control and maintain constant the $\mathrm{pH}$ and
TABLE II

PROGRAM OUPUTS

\begin{tabular}{|c|c|}
\hline Outputs & Function \\
\hline Q0.0 & Recirculating Pump towards Basin(P100) \\
\hline Q0.1 & Recirculating Electro-valve towards Basin (EV103) \\
\hline Q0.2 & Pump. Income Well (P109). \\
\hline Q0.3 & Electro-valve. $1^{\text {st }}$ Stage Mixing (EV100). \\
\hline Q0.4 & Pump. Calcium Hydroxide Preparation (P101) \\
\hline Q0.5 & Mixing Motor .Calcium Hydroxide Preparation (M101). \\
\hline Q0.6 & Pump. Ferric Chloride Preparation (P102). \\
\hline Q0.7 & Pump. Ferric Chloride Tank (P110). \\
\hline Q1.0 & Mixing Motor. Ferric Chloride Preparation (M102) \\
\hline Q1.1 & Mixing Motor. $1^{\text {st }}$ Stage (M105) \\
\hline Q1.2 & Mixing Motor. $1^{\text {st }}$ Stage Decantion Tank (M106) \\
\hline Q1.3 & $\begin{array}{l}\text { Sludge Extraction Electro-valve. } 1^{\text {st }} \text { Stage Decantion } \\
\text { Tank (EV101) }\end{array}$ \\
\hline Q1.4 & Mixing Motor. $2^{\text {nd }}$ Stage (M107) \\
\hline Q1.5 & Mixing Motor. $2^{\text {nd }}$ Stage Decantion Tank (M108) \\
\hline Q1.6 & $\begin{array}{l}\text { Sludge Extraction Electro-valve. } 2^{\text {nd }} \text { Stage Decantion } \\
\text { Tank (EV102) }\end{array}$ \\
\hline Q1.7 & Mixing Motor. Polyelectrolyte Preparation (M103) \\
\hline Q2.0 & Pump. Polyelectrolyte Preparation (P103) \\
\hline Q2.1 & Pump. Aluminium Chloride Tank (P111) \\
\hline Q2.2 & Pump. Aluminium Chloride Preparation (P104). \\
\hline Q2.3 & Mixing Motor. Aluminium Chloride (M104). \\
\hline Q2.4 & $\begin{array}{l}\text { Submergible Pump. Physicochemical Sludge Tank } \\
\text { (P107). }\end{array}$ \\
\hline Q2.5 & Recirculating Pump. Biological Sludge Tank (P108). \\
\hline Q2.6 & $\begin{array}{l}\text { Electro-valve for control of Extraction Pump. } \\
\text { Physicochemical Sludge (EV105A) }\end{array}$ \\
\hline Q2.7 & $\begin{array}{l}\text { Electro-valve for control of Extraction Pump. Biological } \\
\text { Sludge (EV105B). }\end{array}$ \\
\hline Q3.0 & $\begin{array}{l}\text { Electro-valve for control of Extraction Pump. Pools } \\
\text { Sludge (EV104). }\end{array}$ \\
\hline Q3.1 & Extraction Electro-valve. Pools Sludge (EV106). \\
\hline Q3.2 & Extraction Electro-valve. Pools Sludge (EV107). \\
\hline Q3.3 & Extraction Electro-valve. Pools Sludge (EV108) \\
\hline Q3.4 & Air Injection Motor. Pool 2 (M109). \\
\hline Q3.5 & Air Injection Motor. Pool 1 (M110). \\
\hline Q3.6 & Air Compressor (C100). \\
\hline
\end{tabular}

temperature of water coming from the entrance well. To take the measurement, two transducers are used that convert physical quantities, temperature and $\mathrm{pH}$, into two signals of intensity. This signal intensity (Fig. 5) is received by the PLC via an analog module (EM235) that makes the conversion for its interpretation and comparison with the desired values and thus the corrective actions in the system are made. Thus, one of the calculations is the conditioning of the analog sensors. So the $\mathrm{Ph}$ transducer provides as output a variable current signal from 4 to $20 \mathrm{~mA}$ that reads analog module of the PLC and it becomes a 12-bit digital value. This value is stored in the analog input word, AIW0, and because of the signal has a unipolar format, your range 


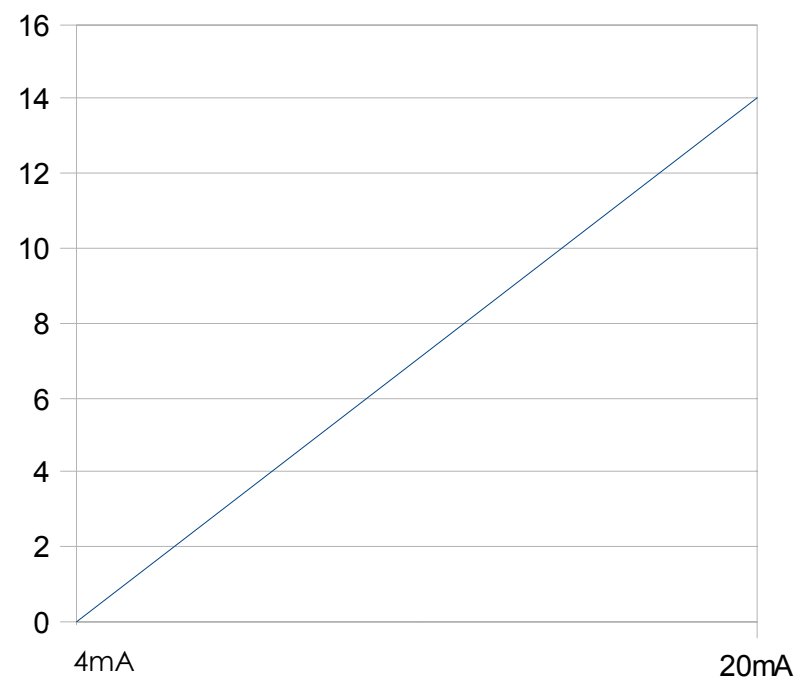

Figure 5. Current's variation in function $\mathrm{Ph}$.

will be between 6400 and 32000 (Fig. 6). Therefore it will be necessary to scale and standardize this variable to the actual range of $\mathrm{pH}$, from 0 to 14 . Using the equation:

$y-y_{0}=m \cdot\left(x-x_{0}\right)$

and solving for the values of the extremes, is obtained the slope of the line depending on the analog input value.

$m=\frac{14}{25600}=0.546 \cdot 10^{-3}$

So the equation to implement in the PLC program to know the real value of $\mathrm{Ph}$ is:

$14-P h=m \cdot(32000-A I W 0)$

So for:

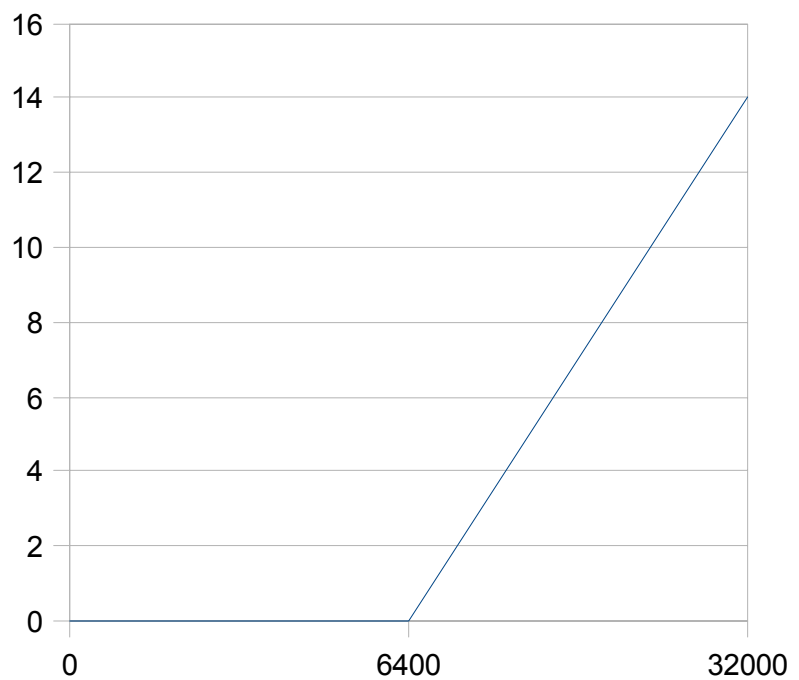

Figure 6. Variation AIWO value in function $\mathrm{Ph}$.

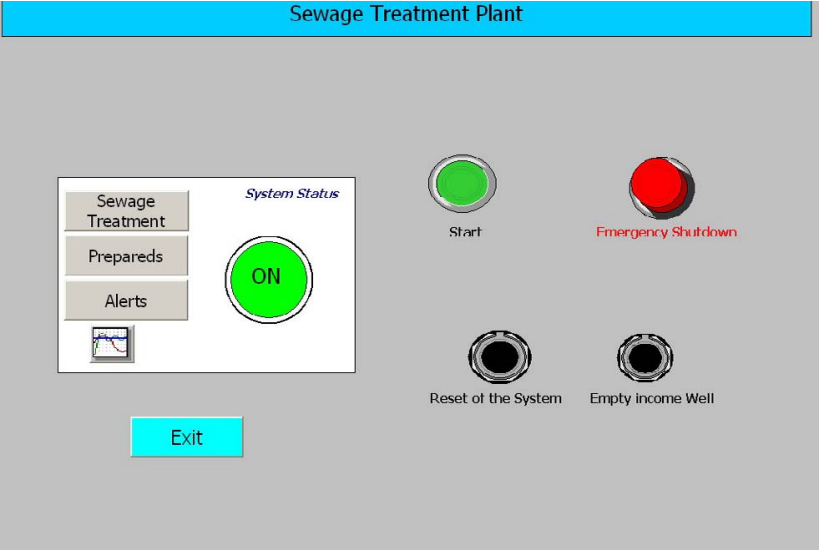

Figure 7. Main Screen Sewage Treatment Plant.

a) $\mathrm{Ph}=5 ; y_{0}=9.71 \mathrm{~mA}=15543$ that is the value to compare in the PLC program as a minimum value of $\mathrm{Ph}$.

b) $\mathrm{Ph}=7 ; y_{0}=12 \mathrm{~mA}=19200$, that is the value to compare in the PLC program the maximum value of $\mathrm{Ph}$.

c) $\mathrm{Ph}=5.8 ; y_{0}=10.63 \mathrm{~mA}=17000$, that is the value to compare in the PLC program as a minimum value of $\mathrm{Ph}$.

\section{Results}

The program is structured in a main screen from that is obtained access to the other four (Fig.7).

\subsection{Main Screen}

The main screen (Fig. 7) gives access to all screens. It allows handling the whole process: start, emergency stop (Fig. 8), reset and empty the entrance well. It also displays the different states of the system.

\subsection{Sewage Treatment Plant Screen}

This screen (Fig. 9) monitors and controls the overall process of purification of the sewage plant.

The state of the system and the different processes are displayed, in addition of showing the levels of $\mathrm{pH}$ and temperature of the water in the entrance well.

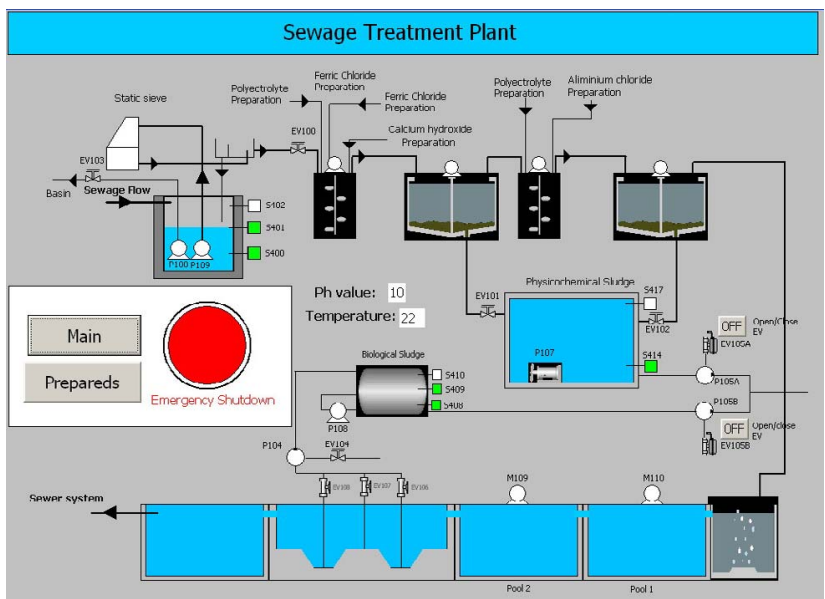

Figure 8. Main Screen Sewage Treatment Plant. 


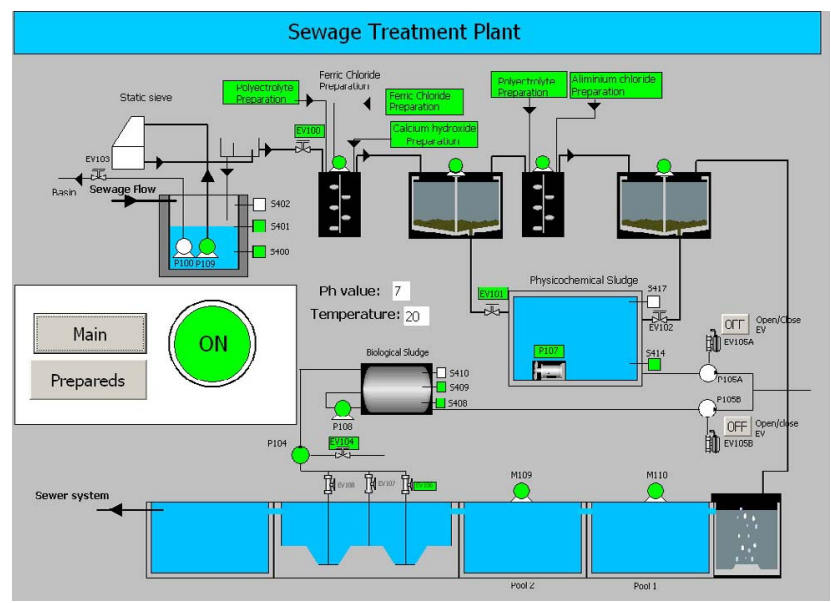

Figure 9. Main Screen Sewage Treatment Plant.

\subsection{Prepared of the Sewage Treatment Plant Screen}

This screen (Fig. 10) displays the different preparations which are going to add to water for physical-chemical treatment of flocculation and coagulation.

Thus, from this screen is possible to control the levels of the different machines needed to perform the different functions in the purification process, such as the pumps and motors.

\subsection{Warnings Screen}

This screen displays warnings and system alarms set up (Fig. 11). In both cases, apart from the source, reflects the date and time.

In the proposed control system, in addition to the specific warnings of the system HMI that reports the state of service, are defined the following:

a) Warnings Service: reporting of irregularities in the service or in the process of the Sewage Treatment Plant, and the effects on the efficiency of the process. These warnings are automatically generated and are a necessary information for the operator in making decisions. For example, inadequate levels of temperature or $\mathrm{pH}$ will be referred to in messages to report this fact

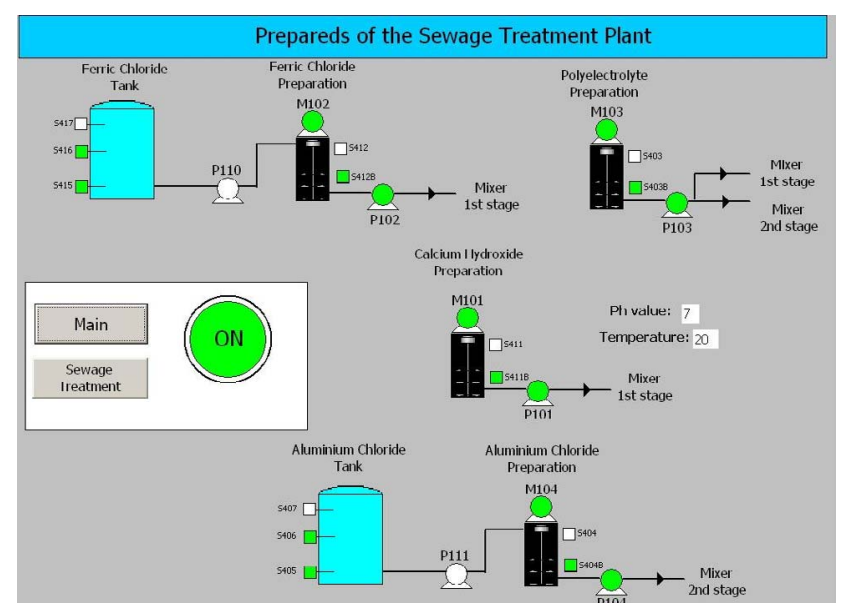

Figure 10. Main Screen Sewage Treatment Plant.

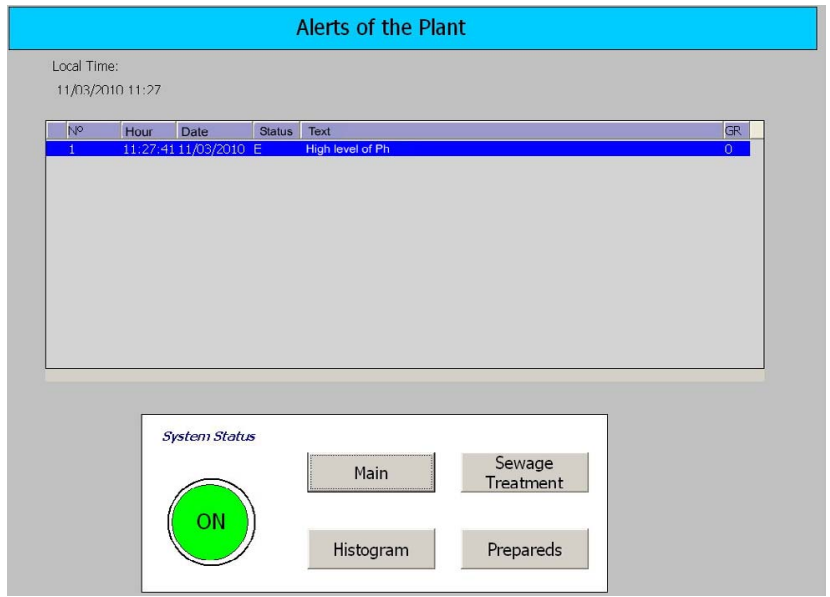

Figure 11. Warnings Screen Sewage Treatment Plant.

(see Figure 11).

b) Alarms: Alarms show states of malfunction or danger in the process. These alarms require mandatory action by an operator after its recognition, and are usually accompanied by the shutdown of the system to remedy the problem. It is distinguished, in this project, among two types of alarms, according to the typology of signal: binary notices for level sensors in the different tanks, and announcements concerning the analogue temperature sensor and $\mathrm{pH}$ sensor, for which it has set an upper limit and lower one involving a failure or risk at the plant.

\subsection{Histogram Screen}

In this screen (Fig. 12) the two analogue variables are displayed, $\mathrm{Ph}$ level and temperature, depending on the time.

\subsection{Variables setting}

In this project, most of the variables are defined as Boolean, since they refer to the inputs or binary outputs as well as internal marks. Its acquisition cycle is 1 second and from "continuous" type, in a way that the variable is updated constantly.

\section{Conclusions}

This paper has been carried out using a process of control, supervision and monitoring of a purification plant intended for the wood Industry. It has been initiated to implement an expert system in the total control of the process and has been complemented with a set of records and alarms. This has revealed in real time the operation state of the process, which allows us to carry out analysis functions, correct them and act appropriately. The choice of a PLC as a control device, not only has guaranteed the interconnectivity and compatibility of the various equipments through interfaces and protocols, but also has also facilitated the interoperability with the used SCADA implementation. 


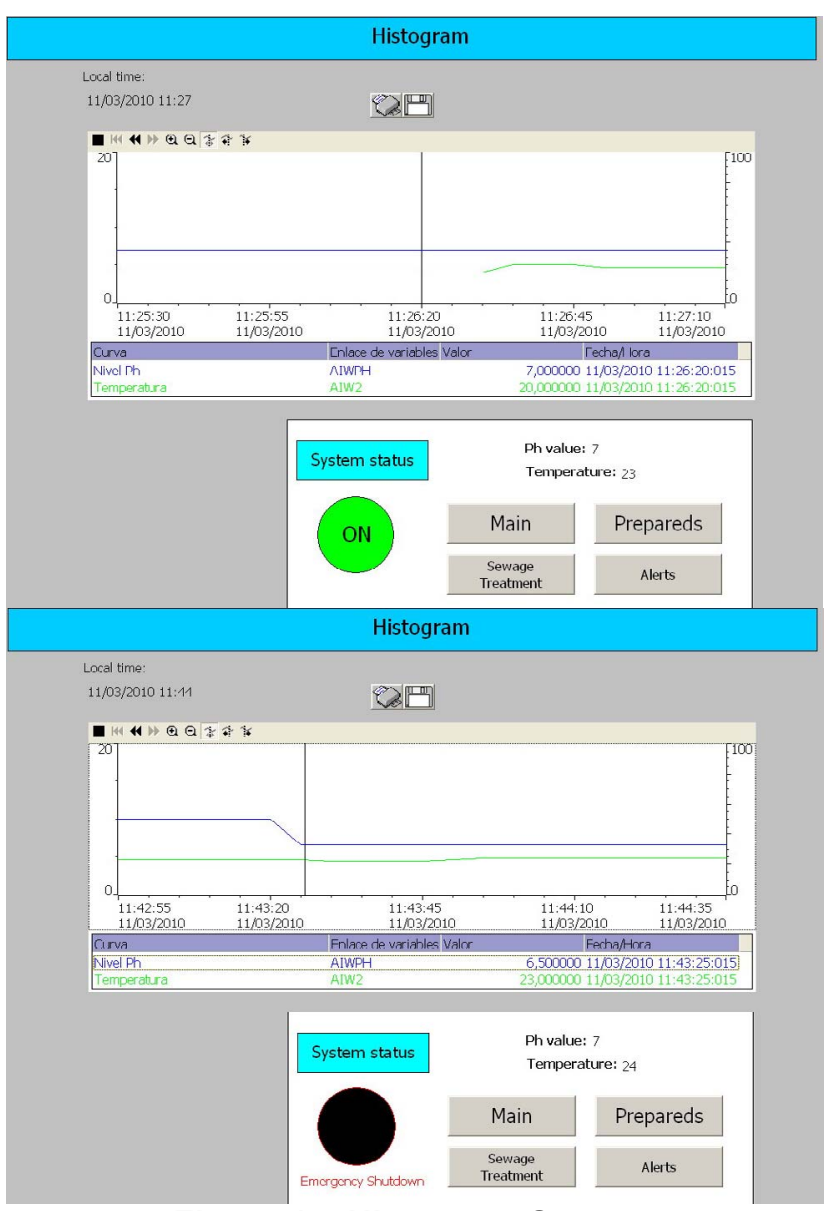

Figure 12. Histogram Screen.

At the same time, there are advantages of allowing using industrial PLC, and especially in this project, it gives flexibility for future upgrades or modifications of the process. The WinCC SCADA with which has been developed the Human-Machine Interface ("HMI") of the system, in addition to its compatibility with the PLC, has helped reduce the processing times of the project due to its versatility and ease of programming. The reduction of the presence in human staff to a single operator, is not detrimental to the operation of the installation, because the expert system proposed improves the quality of work of the operator and minimizes "human error". All this has an impact on increasing the security of the installation, and in short, prioritises environmental protection, the main objective of this process.

\section{Acknowledgment}

The authors wish to thank to Michael Toye by the Linguistic revision done in this paper.

\section{References}

[1] Wang, E.M.-Y.; Kai-Yi Liu; "A human factors improvement on supervisory alarms in wastewater treatment system," Industrial Engineering and Engineering Management, 2009. IE\&EM '09. 16th International Conference on, vol., no., pp.618-621, Beijing, China, 21-23 Oct. 2009

[2] Liao, J.Q.; "Economic analysis on urban domestic sewage treatment," Computing, Communication, Control, and Management, 2009. CCCM 2009. ISECS International Colloquium on, vol.2, no., pp.334-339, Sanya, 8-9 Aug. 2009.

[3] Zhen Zhu; Jiacun Liu; "Remote monitoring system of urban sewage treatment based on Internet," Automation and Logistics, 2008. ICAL 2008. IEEE International Conference on , pp.1151-1155, Qingdao, 1-3 Sept. 2008.

[4] Kang Jiayu; Mi Linan; "An expert system for anaerobic wastewater treatment process," Information and Automation, 2009. ICIA '09. International Conference on, pp.422-425, Zhuhai, Macau, 22-24 June 2009

[5] SIMATIC S7-200 Programmable Controller System Manual, pp. 1999

[6] Siemens, "Autómata Programable S7-200, Configuración, instalación y Datos de la CPU", Ref.: 6ES7-398-8AA03-8DA0, 1998.

[7] Siemens, "Manual de Programación. Software de Sistema para S7-200. Diseño de programas", Ref.: 6ES7-810-4CA04-8DA0, 2000.

[8] Siemens, "Wincc. Manual de Configuración". Vol. 1, Ref.: 6AV6392-1CA05-0AB0, 2005.

[9] Aquilino R. Penin, "Sistemas SCADA". Marcombo S.A, 2006.

[10] C. F. Lindberg, Control and estimation strategies applied to the activated sludge process, Ph.D. dissertation, Uppsala University, Uppsala, Sweden, 1997.

[11] Liting Cao; "Wireless mesh monitoring system for sewage treatment plant," Computing, Communication, Control, and Management, 2009. CCCM 2009. ISECS International Colloquium on , vol.4, no., pp.350-353, . Sanya 8-9 Aug. 2009.

[12] Jingwen Tian; Hao Wu; Meijuan Gao; "Measurement and control system of sewage treatment based on wireless sensor networks", Industrial Technology, 2008. ICIT 2008. IEEE International Conference on, vol., no., pp.1-4. Chengdu 21-24 April 2008.

[13] Lira, V.V.; da Rocha Neto, J.S.; Barros, P.R.; van Haandel, A.C.; "Automation of an anaerobic-aerobic wastewater treatment process," Instrumentation and Measurement, IEEE Transactions on, vol.52, no.3, pp. 909- 915, June 2003. 